\title{
Endocrine-Disrupting Chemicals and Disorders of Penile Development in Humans
}

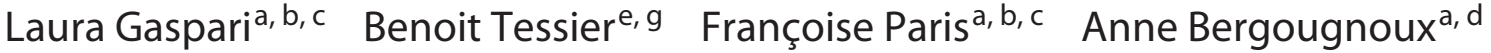 \\ Samir Hamamah ${ }^{c, f}$ Charles Sultan $^{a}$ Nicolas Kalfa ${ }^{a, e, g}$ \\ aCentre de Référence Maladies Rares du Développement Génital DEVGEN, Constitutif Sud, Hôpital Lapeyronie, \\ CHU Montpellier, Université Montpellier, Montpellier, France; bUnité d'Endocrinologie-Gynécologie Pédiatrique, \\ Service de Pédiatrie, Hôpital Arnaud-de-Villeneuve, CHU Montpellier, Université Montpellier, Montpellier, France; \\ 'Développement Embryonnaire Fertilité Environnement, INSERM 1203, Université Montpellier, Montpellier, France; \\ 'Laboratoire de Génétique Moléculaire, PhyMedExp, INSERM, CNRS UMR, CHU Montpellier, Université Montpellier, \\ Montpellier, France; 'Département de Chirurgie Viscérale et Urologique Pédiatrique, Hôpital Lapeyronie, CHU \\ Montpellier, Université Montpellier, Montpellier, France; fDépartement de Biologie de la Reproduction, Biologie de la \\ Reproduction/DPI et CECOS, CHU Montpellier, Université Montpellier, Montpellier, France; 9Institut Debrest de Santé \\ Publique IDESP, UMR INSERM, Université Montpellier, Montpellier, France
}

\section{Keywords \\ Disorders of sex development - Endocrine disruptors . \\ Environment · Hypospadias · Micropenis · Organic \\ chemicals · Penis · Pollution}

\begin{abstract}
This paper reviews the current knowledge on the environmental effects on penile development in humans. The specific focus is on endocrine-disrupting chemicals (EDCs), a heterogeneous group of natural or manmade substances that interfere with endocrine function, and whether they can induce hypospadias and micropenis in male neonates. Epidemiological data and animal observations first raised suspicions about environmental effects, leading to the testis dysgenesis syndrome (TDS) hypothesis. More recent research has provided stronger indications that TDS may indeed be the result of the direct or indirect effects of EDCs. Drawing on epidemiological and toxicological studies, we also report on the effects of maternal diet and substances like pesticides, phthalates, bisphenol A, and polychlorinated biphenyls. Proximity
\end{abstract}

to contamination hazards and occupational exposure are also suspected to contribute to the occurrence of hypospadias and micropenis. Lastly, the cumulative effects of EDCs and the possibility of transgenerational effects, with the penile development of subsequent generations being affected, raise concerns for long-term public health.

() 2021 S. Karger AG, Basel

Hypospadias is a congenital hypoplasia of the ventral surface of the penis characterized by displacement of the urethral meatus, a more or less proximal disjunction of the corpus spongiosum, a short ventral cutaneous radius, preputial dorsal excess, and sometimes ventral curvature of the penis. It is the second most common male genital defect with an estimated prevalence of 3.8 cases per 1,000 male births [Skakkebaek et al., 2001]. Micropenis is defined as a growth restriction of the genital tubercle with penile length less than 2-2.5 SD, i.e., $25-30 \mathrm{~mm}$ in most parts of the world, although this is highly variable according to ethnic groups. Micropenis may be isolated or associated with hypospadias.
Correspondence to:

Nicolas Kalfa, n-kalfa@chu-montpellier.fr 
Although most patients with hypospadias and micropenis present with a mild phenotype (over 50\% have anterior hypospadias), the etiology often remains undetermined and is probably found at the intersection of genetics, endocrinology, and environment. The overwhelming majority of cases remain unexplained, although hypospadias now benefits from next-generation sequencing [Ea et al., 2021]. Genetics may, however, determine a susceptibility to exogenous factors rather than being the sole mechanism of penile defects. Here, we propose a review of the potential targets of endocrine-disrupting chemicals (EDCs) that have been implicated in the occurrence of hypospadias and micropenis and the most recent data on the role of exogenous factors.

\section{Normal Mechanisms of Sex Development in Humans and Potential Targets of EDCs}

\section{Male Sex Differentiation Is a Two-Step Process}

Testis formation or sex determination is regulated by transcriptional factors. The formation and proliferation of the genital ridge requires the action of 6 master genes: Wilms tumor suppressor (WT1), nuclear receptor subfamily 5 group A member 1 (NR5A1, encoding the steroidogenic factor 1), empty spiracles homeobox 2 (EMX2), LIM homeobox 9 (LHX9), and GATA-binding protein 4 (GATA4) [Yang et al., 2018]. The testis determination process is complex and involves a cascade of genes. SRY promotes testis development through the upregulation of SOX9 expression. In mice and human, Sry binds with Sf1 to activate Sox9 enhancers (including testis-specific enhancer of SOX9, TESCO) [Croft et al., 2018]. The other genes are mainly NR5A1, WT1, CBX2 and DMRT1.

The differentiation of internal/external genitalia or sex differentiation is driven by fetal AMH secreted from Sertoli cells and androgens and IGF-1 produced by Leydig cells. Penile development requires several homeobox genes (HOXA, HOXB, and HOXD) [Morgan et al., 2003], BMP4 and BMP7, [Chen et al., 2007], and FGF8 and FGFR2 [Nelson et al., 2007]. Both penile development and urethral closure also require androgens (testosterone and dihydrotestoterone), which act through the androgen receptor (AR) [Kalfa et al., 2019]. Micropenis belongs to the spectrum of androgen insensitivity. The urethra closes as a double zipper mechanism [Baskin et al., 2018]. Genital differentiation in boys is based on an androgenestrogen equilibrium. The estrogen receptors ESR1 and ESR2 are expressed in the genital tubercle of the fetal male [Crescioli et al., 2003]. SNPs of ESRs and a CA-repeat in ESR2 increase the risk of hypospadias [Deng et al., 2016].

\section{Substances, Routes of Contamination, and Mechanisms of Sex Development Disruption}

\section{Overview}

EDCs constitute a heterogeneous group of natural or man-made substances that interfere with endocrine function [Knez, 2013]. The mechanisms of disruption include: (1) the direct binding to estrogen receptor (ER) a and $E R \beta$ and modification of the activation or repression of the transcription of specific genes, (2) non-genomic action via membrane ERs, (3) induction and transformation into a more active estrogenic metabolite, (4) competition with endogenous estrogens for binding to sex hormone binding globulin, (5) inhibition of the transcription of androgen-dependent genes, (6) synergistic effects of the previously cited mechanisms, and (7) suspicion of oncogenic effects. There are multiple routes of contamination, as humans are in constant contact with these substances [Garry et al., 1996; Brock et al., 1998], which are present in water, soil, food, and air [Olea et al., 1999] and can enter the body by ingestion, inhalation, and adsorption. These substances are often lipophilic and thus stored in adipose tissue for many years [Kelce et al., 1995]. They can also be found in breast milk and amniotic fluid [Sonawane, 1995].

EDC exposure in utero may lead to developmental abnormalities in males. Regarding reproductive health, testis dysgenesis syndrome (TDS) [Skakkebaek et al., 2016], which includes cryptorchidism, hypospadias, micropenis, poor semen quality, and a predisposition to testicular cancer, was initially assumed to be related to the inhibition of androgen action on fetal development. Recent data, however, indicate that it may also result from the direct or indirect effects of EDCs. Experimental data have confirmed the impact of fetal exposure to EDCs in the development of gonadal dysgenesis [Lara et al., 2017; Abdel-Maksoud et al., 2019]. Lara et al. [2017] reported that prenatal exposure to dibutylphthalate (DBP) induced a focal dysgenetic area in fetal testis and reduced androgen production. The disruption of both fetal Leydig and Sertoli cells by DBP and the late reproductive consequences may be related to environmental EDCs.

\section{Classes of EDCs}

A summary of the different classes of EDCs is shown in Table 1.

Persistent organic pollutants (POPs) are organic compounds that are highly resistant to environmental degradation, with half-lives in the environment and living organisms in the range of several months to years [Nadal 
Table 1. Endocrine-disrupting chemicals and disorders of penile development in humans

\begin{tabular}{|c|c|}
\hline Endocrine-disrupting chemical & References \\
\hline Pesticides/insecticides & $\begin{array}{l}\text { Kristensen et al. [1997]; Morera et al. [2006]; Sun et al. [2009]; Dugas et al. [2010]; } \\
\text { Nassar et al. [2010]; Gaspari et al. [2011a, 2012]; Brouwers et al. [2007, 2010]; Kalfa et } \\
\text { al. [2015]; Garcia et al. [2017]; Cognez et al. [2019] }\end{array}$ \\
\hline $\begin{array}{l}\text { Dichlorodiphenyltrichloroetane (DDT) and/or its metabolite } \\
\text { dichlorodiphenyldichlorethane (DDE) }\end{array}$ & $\begin{array}{l}\text { Longnecker et al. [2002]; Flores-Luevano et al. [2003]; Rignell-Hydbom et al. [2012]; } \\
\text { Gaspari et al. [2012]; Winston et al. [2016] }\end{array}$ \\
\hline Trans-nonachlor and oxychlordane & Trabert et al. [2012] \\
\hline Atrazine & Agopian et al. [2013]; Winston et al. [2016] \\
\hline $\begin{array}{l}\text { Phenylurea herbicide isoproturon and phenoxyherbicide } \\
\text { 2-methyl-4-chlorophenoxyacetic acid (MCPA) }\end{array}$ & Carmichael et al. [2013]; Haraux et al. [2018] \\
\hline Trihalomethanes (THM) and haloacetic acids (HAA) & Luben et al. [2008]; Iszatt et al. [2011] \\
\hline Tetrachlorethylene & Aschengrau et al. [2018] \\
\hline $\begin{array}{l}\text { Diethylhexylphthalate (DEHP), diisononylphthalate (DINP), } \\
\text { dibutylphthalates (DBP) }\end{array}$ & $\begin{array}{l}\text { Chevrier et al. [2012]; Choi et al. [2012]; Watkins et al. [2014]; Jensen et al. [2015]; } \\
\text { Marie et al. [2015]; Sathyanarayana et al. [2017]; Radke et al. [2018] }\end{array}$ \\
\hline Bisphenol A (BPA) & Choi et al. [2012]; Fernandez et al. [2016a] \\
\hline Polychlorinated biphenyl (PCB) & Dolk et al. [1998];McGlynn et al. [2009]; Carmichael et al. [2010] \\
\hline Per- and polyfluoroalkyl substances (PFASs) & Vesterholm Jensen et al. [2014]; Toft et al. [2016]; Petersen et al. [2020] \\
\hline Glycol ethers and/or its metabolites (methoxyacetic acid) & Warembourg et al. [2018] \\
\hline Hexachlorobenzene (HCB) & Giordano et al. [2010]; Rignell-Hydbom et al. [2012] \\
\hline Polybrominated diphenyl ethers (PBDEs) & Lee and He, [2010]; Poon et al. [2018]; Koren et al. [2019] \\
\hline Dioxin (TCDD) & Mastroiacovo et al. [1988] \\
\hline Nitrogen dioxide $\left(\mathrm{NO}_{2}\right), \mathrm{O}_{3}$, and PM10 and PM2.5 air pollutants & Salavati et al. [2018]; Huang et al. [2020]; Lin et al. [2021] \\
\hline Heavy metal hazardous air pollutants (HMHAP) & White et al. [2019] \\
\hline Phytoestrogens & Pierik et al. [2004]; Michikawa et al. [2019] \\
\hline Fish consumption & Akre et al. [2008]; Giordano et al. [2008] \\
\hline
\end{tabular}

and Domingo, 2013]. POPs most routinely detected in environmental and thus human samples that are reported to have endocrine-disrupting properties include per- and polyfluoroalkyl substances (PFASs), brominated flame retardants (BFRs), and organochlorine pesticides, among others. In addition to POPs, there are non-persistent environmental chemicals such as bisphenols, phthalates, parabens, synthetic pyrethroids, and organophosphate pesticides, which have relatively short half-lives in the human body and do not accumulate significantly [Diamanti-Kandarakis et al., 2009].

PFASs are a family of fluorinated aliphatic compounds manufactured for diverse applications [Sunderland et al., 2019]. They are used in oil/water repellant textiles, food packaging, cleaning products, and firefighting foams [Frisbee et al., 2009]. PFASs are not easily degraded under environmental conditions [Wang et al., 2013]. Humans come into contact with them via contaminated water, food, and air [Vestergren et al., 2008]. PFASs have been detected in blood, milk, urine, umbilical cord, breast milk, hair, and nails [Wang et al., 2018]. Several molecular mechanisms were identified for their action, including PPARa antagonism, ROS generation, direct inhibition of $\mathrm{T}$ synthesis and metabolism, and indirect inhibition of glucocorticoid metabolism [Zhu et al., 2020].

BFRs are chemicals applied to various materials to reduce their flammability. This family of 209 possible chemicals (congeners) are structurally similar to PCBs [Lyche et al., 2015]. The most commonly used are polybrominated diphenyl ethers (PBDEs), hexabromocyclododecane (HBCDD), and tetrabromobisphenol A (TBBPA). They have become ubiquitous environmental 
contaminants and can be detected in air, water, soil, fish, birds, and mammals, including humans [Hites, 2004]. Because most BFRs are highly lipid soluble, fatty fish, fish oils, and fatty foods of animal origin are potential sources for human exposure [Lyche et al., 2015]. PBDEs are also able to penetrate the placenta, making intrauterine exposure to PBDEs in the human fetus possible [Tang and Zhai, 2017]. The endocrine-disrupting potency of BFRs is illustrated by the interaction of various congeners with estrogen, progesterone, and androgen receptors [Meerts et al., 2001; Hamers et al., 2006].

Dioxins are a group of chlorinated organic chemicals that are unfortunate by-products of manufacturing processes that include pesticide manufacturing, chlorine bleaching of paper pulp, combustion, and waste incineration. Moreover, humans were exposed to dioxins through contamination by Agent Orange during the Vietnam War and the industrial explosion in the Seveso disaster in Italy [Weiss et al., 2003; Tai et al., 2011]. Both incidents resulted in high and long-term dioxin exposure in humans. Tetrachlorodibenzo-p-dioxin (TCDD) is a wellknown dioxin that belongs to the dioxin/dioxin-like family of environmental contaminants [Bruner-Tran et al., 2017]. Dioxins are lipophilic and highly stable, have halflives ranging from 7 to 11 years in humans, and are excreted in breast milk [Weiss et al., 2003; Tai et al., 2011]. Among human and animal populations, ingestion of contaminated food is the primary source of dioxin exposure [Harrad et al., 2003; Malisch and Kotz, 2014; EFSA Panel on Contaminants in the Food Chain (CONTAM) et al., 2018]. Esser et al. [2005] reported that TCDD produces toxic effects by interfering with the physiological signaling of AHR. In particular, dioxins were shown to block ER action [Safe, 2001] and have antiandrogenic action [Mai et al., 2020].

Bisphenols are man-made organic chemicals that are produced throughout the world. The most common and widely used analog of bisphenol, bisphenol A [BPA; 2,2-bis(4-hydroxyphenol)propane], is mainly used in the production of polycarbonate plastics and epoxy resins. Polycarbonate plastics are used in water bottles, toys, CDs, food and beverage packaging, plastic tableware, flame retardants, medical, dental, and optical devices, computers, wire insulation, and thermal paper. Epoxy resins are used as lacquers to coat metal products like food cans, bottle tops, and water supply pipes [Shafei et al., 2018; Stillwater et al., 2020]. BPA is also found in dust, laminate flooring, paints, and home electronics [Shafei et al., 2018; Stillwater et al., 2020]. Since 2012, the FDA has banned it from use in plastic baby bottles, sippy cups, and baby formula packaging [Stillwater et al., 2020]. However, its use has continued for many years in non-infant applications like food packaging. BPA is being gradually removed from consumer products, with a corresponding move toward its derivatives: bisphenols F, E, B, and S as materials for polycarbonate resin [Kitamura et al., 2005]. Yet, as these alternative bisphenols are structurally similar to BPA, they are suspected of having equivalent toxicological effects [Yilmaz et al., 2020]. According to the literature, at least 2 substitutes, BPS and BPF, are as hormonally active as BPA and have endocrine-disrupting effects [Rochester and Bolden, 2015].

Phthalates are esters of 1,2-benzenedicarboxylic acid and their structure varies with the number of side chains, which are formed by dialkyl, alkyl, or aryl groups [Benjamin et al., 2015]. Phthalates are used as plasticizers in many products, especially medical devices like intravenous (IV) bags and tubing, umbilical artery catheters, blood bags and infusion tubing, enteral nutrition feeding bags, nasogastric tubes, and peritoneal dialysis bags. They are also used in manufacturing a wide variety of consumer products, such as packaged foods and beverages, soft plastic products like toys and infant products [Earls et al., 2003], building and furniture materials, including furniture upholstery, mattresses, wall coverings, floor tiles, and vinyl flooring, and cosmetics and personal care products to carry fragrances [Koniecki et al., 2011; Dobrzynska, 2016; Rowdhwal and Chen, 2018].

Unlike POPs, plasticizers like bisphenols and phthalates are water soluble and do not bioaccumulate in the body. However, due to their overuse in many products, they can be found in air, water, and soil. Humans are daily exposed to plasticizers via dermal and oral exposure and inhalation, but most exposure is oral. Once BPA and analogs are absorbed into the body, they are able to bind to ER $\alpha$ and $\beta$, mimicking estrogen-like properties [Paris et al., 2002]. They can also act with $G$ protein-coupled ER (GPER30) and interfere with estrogen-activated signaling pathways [Chevalier et al., 2012; Acconcia et al., 2015; Nadal et al., 2018; Sheng et al., 2019]. Moreover, BPA can also bind to the AR and act as its antagonist [Huang et al., 2019]. Phthalates influence the activity of the AR and ER, leading to the impaired action of endogenous signal molecules on hormone-dependent tissue. In particular, they act as agonists (DEP, DnBP, DiBP, BBzP, DiNP, DEHP, DCHP) and antagonists (DnBP, BBzP, DEHP, DCHP) of the ER and as agonists (DnBP, DEHP) and antagonists (DnBP, DiBP, BBzP, DEHP, DCHP) of the AR [Hlisnikova et al., 2020]. 
Pesticides enter the soil by direct treatment or by being washed off from the plant surface during rainfall [Annamalai and Namasivayam, 2015]. Although all classes of pesticides can produce adverse effects on human health, organochlorine pesticides (OCPs) pose the greatest risk as EDCs, because they are relatively hydrophobic, resistant to degradation, and able to accumulate in soils and sediments [Annamalai and Namasivayam, 2015; Yilmaz et al., 2020]. Populations are exposed daily via ingestion, inhalation, and dermal contact [Brehm and Flaws, 2019].

Some OCPs are structurally similar to E2 and are able to bind to the ER and mimic the effects of the endogenous ligand [Zhang et al., 2020]; other OCPs, like glyphosate and atrazine, are reported to increase aromatase expression and activity in cells [Richard et al., 2005; Gasnier et al., 2009; Zhang et al., 2020]. Moreover, atrazine has antiandrogenic properties [Kniewald et al., 1995]. DDT and its metabolites (o,p-DDT, and p, p'-DDE) have estrogenic effects by blocking the AR [Paris et al., 2002].

Heavy metals are found in practically all environmental compartments: air, water, soil, and living organisms, where they act as EDCs [Wirth and Mijal, 2010]. The general population is exposed to them via contaminants found in drinking water and food [Wirth and Mijal, 2010]. Martin et al. [2007] identified a new class of potent environmental estrogens, calling them metalloestrogens. These metals and metalloids (i.e., cadmium, cobalt, nickel, lead, mercury, arsenite) mimic the effects of estradiol by activating ERa through a high-affinity interaction with the hormone-binding domain of the receptor [Martin et al., 2007]. In addition, heavy metals, such as cadmium, have the ability to disrupt steroidogenesis by interfering with the biosynthesis of androgens [Georgescu et al., 2011].

Phytoestrogens are mostly found in the diet and are isoflavones and lignans. The main food sources are legumes, particularly soy, although, they are contained in smaller quantities in fruits, vegetables, and cereals [Hu et al., 2014]. Phytoestrogens may act by ER-mediated genomic and non-genomic mechanisms [Viggiani et al., 2019]. In general, phytoestrogens bind to ERs and behave like weak agonists.

Ambient fine particulate matter (PM2.5) pollutants, like astropospheric ozone $\left(\mathrm{O}_{3}\right)$, sulfur dioxide $\left(\mathrm{SO}_{2}\right)$, nitrogen dioxide $\left(\mathrm{NO}_{2}\right)$, and carbon monoxide $(\mathrm{CO})$, are of public health concern worldwide. PM2.5 can penetrate into blood, carrying many of the above-mentioned metalloestrogen heavy metals and polycyclic aromatic hydrocarbons (PAHs) [Gao et al., 2018]. PAHs are estrogenic or antiestrogenic [Zhang et al., 2016] through a direct in-

EDCs and Disorders of Penile Development teraction between PAHs and ERs (estrogenic) and the AHR-mediated suppression of estrogenic activity (antiestrogenic) [Arcaro et al., 1999; Zhang et al., 2016].

\section{EDCs and Placenta}

In addition to these mechanisms, EDCs may act on fetal development through the placenta. Placental HCG stimulates steroidogenesis of the fetal testis even before the fetal gonadotropic axis is functional. Placental insufficiency can therefore be associated with fetal HCG insufficiency, which would explain the association between hypospadias, intrauterine growth retardation (IUGR), and low birth weight. The IUGR/hypospadias combination has been widely reported [Akre et al., 1999; Hughes et al., 2002; Boisen et al., 2005]. In twin pregnancies, IUGR is more common in the twin with hypospadias [Chambers et al., 2006]. The association between low placental weight and the occurrence of hypospadias is strong [Stoll et al., 1990], although it should be noted that the association is stronger in posterior forms of hypospadias [Ghirri et al., 2009; Brouwers et al., 2010]. During embryonic development, EDCs can alter placental cell division, placental differentiation, determination of placental cell lines, DNA methylation, implantation, and the maintenance of pregnancy and organogenesis. PCBs, dioxins, and phthalates impair the differentiation of certain cell lines and trophoblast function in the blastocyst, cross the placental barrier, and alter embryonic development in humans [Myatt, 2006]. For example, a high concentration of 5 phthalate metabolites (MEHP, MEOHP, MnBP, $\mathrm{MiBO}, \mathrm{MBzP})$ in the serum of pregnant women was associated with a reduction in the expression of trophoblast differentiation markers (PPAR $\gamma, \mathrm{hCG}$ ) and an alteration in placental function [Adibi et al., 2010]. These same substances are able to alter the functioning of human endometrial cells via the AHR receptor [Willing et al., 2011]. In mice, exposure to PCBs increases the AHR signal and other genes required for implantation (VEGFR-2 and COX-2) [Clausen et al., 2005]. Dioxin, via this same signaling pathway, decreases the expression of glucose transporter 1 (GLUT1), which alters embryonic glucose uptake. Among other potentially toxic elements, cadmium acts as a metal estrogen [Guillette, 2006]. One of the main sources of cadmium during pregnancy is tobacco smoke. This substance alters the normal trophoblast functioning by downregulating leptin [Stasenko et al., 2010]. Leptin, as an adipokine, is an antiapoptotic and cell proliferation factor that is important for the maintenance of the placenta [Perez-Perez et al., 2008]. EDCs stimulate a stress response in the placenta, inducing the expression of stress 
proteins (e.g., HSP70 and MAPK protein phosphorylation) that can inhibit trophoblast differentiation and invasion, thereby impairing further placental function.

\section{Arguments from Animal Observations for the Role of EDCs in Human Sex Development}

Hypospadias, whether associated with micropenis or not, has been reported in many wild species whose habitat is contaminated by pesticides [Hayes et al., 2002]. The effects of prenatal xenoestrogens on the development of the reproductive tract in male animals have been studied by several groups. The first generations of rats exposed during intrauterine life to synthetic estrogens (at concentrations similar to those measured during the first trimester in humans) developed hypospadias [Gray and Kelce, 1996]. Hypospadias was also described in rodents after maternal treatment with vinclozolin (a fungicide-type pesticide), showing a dose-effect response [Gray et al., 2001]. Similar results have been obtained following prenatal exposure to PCBs (polychlorinated biphenyls), phthalates, and dioxin [Baskin et al., 2001; Gray et al., 2001; Fisher et al., 2003]. The extrapolation of these animal studies to humans has nevertheless been questioned. Animal studies use concentrations of substances higher than those found in the environment [Sharpe and Skakkebaek, 2008]. In addition, the intrinsic estrogenic or antiandrogenic effects of these substances are lower than those of diethylstilbestrol (DES), which is often used as an experimental model. However, a synergistic effect of the combination of several substances has been demonstrated even at low doses [Ivell and Hartung, 2003].

\section{Is There an Increased Incidence of Hypospadias and Micropenis that Could Point toward EDCs and TDS?}

The prevalence of hypospadias is relatively high, although it varies widely depending on country and ethnicity. The mean prevalence per 10,000 live births ranges as follows: Europe 19.9 (range: 1-464), North America 34.2 (6-129.8), South America 5.2 (2.8-110), Asia 0.6-69, Africa 5.9 (1.9-110), and Australia 17.1-34.8 [Springer et al., 2016]. We reported a particularly high prevalence in the south of France $(97 / 10,000)$ [Gaspari et al., 2011a] and Brazil $(55 / 10,000)$ [Gaspari et al., 2012].

Over the past 10 years, questions about the increasing incidence of hypospadias have been raised repeatedly, raising the suspicion of an exogenous and environmental cause. However, the conclusions of epidemiological studies are not unequivocal. The oldest studies suggested an increase in hypospadias rates, and 11 studies published between 1975 and 1997 came to this conclusion for the years between 1964 and 1995 [Paulozzi, 1999]. The first publications in the 1960s and 1970s were based on a small number of countries mainly in North America and Europe. In 1997, Paulozzi et al. used data from the Birth Defects Monitoring Program (BDMP) and reported that the incidence of hypospadias in the USA doubled between 1970 and 1993. The data collection methods in this study were questioned as the sample was not representative of the US population and was in fact ill defined [Edmonds et al., 1981]. These initial reports of an increase in the number of hypospadias cases have various explanations: influence of an external environmental factor, variation in the definition of the hypospadias in the included cases, improved screening for malformations with increasingly better trained doctors, and the increased demand for complete correction. Newer studies show contrasting results. A retrospective study carried out in New York State showed that the rate of hypospadias decreased from 1983 to 2005 with a prevalence dropping from $36.34 / 10,000$ births in 1983 to $35 / 10,000$ births for the period 1992-2005 [Fisch et al., 2009]. In California, the rate of hypospadias seemed stable from 1984 to 1997 [Carmichael et al., 2003]. In Washington State, the prevalence in 2002 ( 5 cases per 1,000 births) appeared to be similar to that in 1987 [Porter et al., 2005]. In Europe, the prevalence of hypospadias also appeared to be stable. A European study carried out in 20 regions and based on European registers from 1980 to 1999 showed no significant increase in its prevalence [Dolk et al., 2004]. A larger study drawing on 29 national registers and including 4 million births per year throughout the world confirmed this stability in most cases but showed an increase in the rate of hypospadias in 2 registers (Scandinavia and Japan), particularly from 1970 to 1980 [Paulozzi et al., 1997]. An exhaustive collection of cases and precise anatomical definition data are particularly important: they refine the results to the point of revealing differences in trends between studies, as in Japan [EUROCAT, 2003]. Taking into account the range of phenotypes, the prevalence seems to have increased in certain geographic areas, including North America (e.g., in Arkansas, the prevalence rose from 67/10,000 births in 1998 to 81/10,000 births in 2007) [Canon et al., 2012]. A striking element that points toward TDS is the positive correlation between hypospadias and testicular cancer and between hypospadias and undescended testis. These correlations emerge more clearly in high-quality registers [Serrano et al., 2013]. 
Epidemiological studies of micropenis have reported wide differences in prevalence: from $0.015 \%$ of the US population [Nelson et al., 2005] and $0.062 \%$ of the Egyptian population [Mazen et al., 2010] to $0.35 \%$ in southern France [Gaspari et al., 2011a] and $0.66 \%$ in northeastern Brazil [Gaspari et al., 2012]. To our knowledge, no epidemiological study has reported the evolution of micropenis prevalence over decades, and specific data on micropenis remain sparse for several reasons. Notably, micropenis, which is defined as penile length less than 2-2.5 SD, i.e., $25-30 \mathrm{~mm}$ in most parts of the world, may have been underdiagnosed for years. Measurement of the stretched penis is standardized, but it is not highly reproducible. It may be isolated or associated with other defects, such as hypospadias and undescended testis.

\section{EDCs and Hypospadias}

\section{Maternal Diet}

The effects of a maternal vegetarian diet on the occurrence of hypospadias remain under debate as this diet has been reported to increase the risk of hypospadias as much as 5-fold [North and Golding, 2000; Akre et al., 2008] and yet sometimes has no effect [Brouwers et al., 2010]. Two hypotheses have been suggested. First, the effects may be related to the mother's consumption of phytoestrogens (a vegetarian diet is high in isoflavones contained in soy food), which then affects the developing fetus. Yet, a 2004 study based on a questionnaire about the mother's intake of phytoestrogens [Pierik et al., 2004] did not seem to confirm this hypothesis. Other works have even shown a contrary effect and pointed to the antioxidative role of these substances [Michikawa et al., 2019]. The other hypothesis is linked to fish consumption because of the accumulation of toxic products in this type of food [Giordano et al., 2008]. Again, the contradictory data prevent definitive conclusions from being drawn [Akre et al., 2008]. The consumption of organic foods has shown no protective effect in some studies [Christensen et al., 2013]. In contrast, a Norwegian study on more than 35,000 women showed that those who consumed organic food during pregnancy were less likely to give birth to a hypospdiac boy (OR 0.42), but this was based on 21 cases only.

\section{Pesticides and Hypospadias}

Pesticides are the very prototype of EDCs and in this sense have been widely studied in the context of hypospadias occurrence [Raghavan et al., 2018]. Maternal expo-

EDCs and Disorders of Penile

Development sure has been the major focus, and maternal involvement in agricultural activities that include insecticide use increased the risk of hypospadias in 2 studies [Sun et al., 2009; Dugas et al., 2010]. These data nevertheless remain debatable, because studies on the domestic use of pesticides provide contrasting results [Dugas et al., 2010; Nassar et al., 2010; Gaspari et al., 2012]. Direct measurements of EDCs in mothers also provide divergent results. A high concentration of dichlorodiphenyltrichloroethane (DDT) and its metabolite dichlorodiphenyldichloroethane (DDE) or chlordane derivatives (trans-nonachlor and oxychlordane) in maternal plasma during pregnancy has not been associated with an increased risk of hypospadias [Longnecker et al., 2002; Flores-Luevano et al., 2003]. Nevertheless, a large study found an increased risk of hypospadias among women with a higher serum DDE concentration during the 14th week of gestation [RignellHydbom et al., 2012]. Moreover, we reported a relatively high prevalence of hypospadias $(55 / 10,000)$ among newborns in northeastern Brazil, whose mothers reported daily domestic use of pesticides before and during pregnancy, especially DDT, to control insect proliferation [Gaspari et al., 2012].

The pesticide atrazine, found in public drinking water, also raises concerns. One study showed an increasing risk of hypospadias, with an OR ranging from 1.11 to 1.52 depending on the level of exposure, and a stronger correlation with severe phenotypes [Agopian et al., 2013]. This was not confirmed by another series based on the $\mathrm{Na}$ tional Birth Defects Prevention Study using data from groundwater contaminant models from the US geological survey to assess contamination in public water supplies and in private wells after geocoding [Winston et al., 2016]. Other contaminants may be found in water, called disinfection byproducts (DBPs), including trihalomethanes (THMs) and haloacetic acids (HAA). Two case-control studies, based on national data on the THM concentration in water, did not confirm this hypothesis [Luben et al., 2008; Iszatt et al., 2011]. Tetrachlorethylene is another water contaminant, particularly in Massachusetts and Rhode Island. Between 1968 and 1995 [Aschengrau et al., 2018], mothers with high exposure to this substance during the first trimester of pregnancy had an increased risk of hypospadias, although the confidence interval was wide (OR 2.1; 95\% CI, 0.5-8.3).

Meconium is another possible matrix as it may be a good marker of chronic exposure [Esteban and Castano, 2009]. In this study, the authors focused on the pesticides used in the study area. They found an association between hypospadias and the presence of phenylurea herbicide 
isoproturon and phenoxyherbicide 2-methyl-4-chlorophenoxyacetic acid (MCPA) in meconium, with a high but wide OR range [Haraux et al., 2018]. MCPA acts as an EDC [Benassou, 2016] and is one of the pesticides identified as a risk factor in previous studies [Carmichael et al., 2013].

Paternal exposure should also be considered. Some authors found no link between the father's pesticide exposure and the occurrence of hypospadias in the child [Brouwers et al., 2007, 2010; Nassar et al., 2010], whereas others showed evidence of the role of such exposure [Kristensen et al., 1997; Kalfa et al., 2015]. In our nested case-control study, the self-reported occupational exposure to pesticides by both parents was a statistically significant risk factor for male genital malformations (OR 4.41; 95\% CI, 1.21-16.00) [Gaspari et al., 2012]. We were unable to separate the mothers' occupational exposure from that of the fathers because, in both the cases and controls, the 2 parents worked together as farmers, wineand rice-growers, tree and fruit farmers, or gardeners. In addition, these family units reported also living in the countryside, which added potential environmental contamination by pesticides to the occupational EDC exposure.

\section{Phtalates, Bisphenol A, and Hypospadias}

Phtalates have been particularly explored since the 2010s and have shown an effect on the testis in animal models [Czubacka et al., 2020]. Phtalates pose a methodological challenge for researchers as their half-lives are short and they are ubiquitous. It is thus difficult to precisely assess the level of exposure to phtalates during the windows of masculinization since most studies focus on measurement in urine, which may be highly variable even in a single individual. One case-control study used amniotic fluid samples from the second trimester [Jensen et al., 2015] to measure the concentrations of diethylhexylphthalate (DEHP) and diisononylphthalate (DINP) metabolites. Only the DINP metabolites tended to be associated with hypospadias, but this did not reach significance. Advanced maternal age and the presence of other developmental abnormalities may be confounding factors [Raghavan et al., 2018]. Other studies mainly used urine samples at birth and did not correctly study exposure during fetal life [Watkins et al., 2014]. One study found an association between hypospadias and a high level of DEHP [Choi et al., 2012]. This finding was not reproduced when DEHP was measured in maternal urine [Chevrier et al., 2012; Choi et al., 2012]. Sathyanarayana et al. [2017] studied the association between urine DHP in early pregnancy, serum free testosterone, E1 and E2, and newborn development outcome. They found a positive relationship between DEHP metabolites and E1 and E2 levels and a negative relationship with free testosterone, with no correlation with anogenital distance, although higher testosterone levels reduce the risk of a genital defect. Some authors have used placenta to measure phtalate exposure [Fernandez et al., 2016a] using liquid chromatography-tandem mass spectrometry. They found an association between exposure to BPA and male defects. Overall, a review on phthalates and obstetrical outcome confirmed the possible effect on the anogenital distance but provided contradictory results regarding hypospadias, as they depended on the phenotype included in the series and the quality of controls [Marie et al., 2015]. A recent systematic review focused on 6 phthalates, including DEHP, DINP, and dibutylphthalates (DBP) [Radke et al., 2018]. There was robust evidence of an association between DHEP and DBP exposure and male reproductive outcome, mainly based on anogenital distance, testosterone level, and semen quality. Regarding hypospadias specifically, the results were inconsistent, and the evidence was considered slight or indeterminate.

\section{Other Endocrine-Disrupting Chemicals}

Another EDC that may induce hypospadias is polychlorinated biphenyl (PCB). A case-control study of almost 800 children found no correlation between serum levels of 11 PCBs and genital defects [McGlynn et al., 2009] nor did a smaller study [Dolk et al., 1998]. This negative result was further confirmed by US [Carmichael et al., 2010] and Swedish [Rignell-Hydbom et al., 2012] series, even in association with other EDCs, like HCB [Rignell-Hydbom et al., 2012] and flame retardants [Carmichael et al., 2010].

Several other substances have been explored. A recent systematic review of 26 eligible studies evaluated the effects of PFAS on the male human reproductive tract $[\mathrm{Pe}-$ tersen et al., 2020]. The 2 main studies on this topic [Vesterholm Jensen et al., 2014; Toft et al., 2016] found no positive association with hypospadias. Flame retardants, including polybrominated diphenyl ethers (PBDEs), have also been suspected. These are strong EDCs, and humans are exposed to them via inhalation of household or workplace dust. Mothers of hypospadias children were found to have been exposed to significantly higher levels of PBDEs than controls, according to a study that directly measured 8 PBDEs in maternal hair by gas chromatography-mass spectroscopy [Poon et al., 2018]. The less brominated PBDE congeners exhibit a higher body 
burden in mothers of boys with hypospadias [Lee and He, 2010; Koren et al., 2019]. Glycol ethers, a family of oxygenated solvents, were examined in a case-control study using spot maternal urine samples. Hypospadias was associated with the higher tertile of one of its metabolites (methoxyacetic acid), but the sample size of the population remained limited [Warembourg et al., 2018]. Benzene derivatives are also reported to be found in higher concentrations in the mothers of hypospadiac children [Giordano et al., 2010].

\section{Hypospadias and Proximity of Contamination \\ Hazards}

The geographic proximity to contamination zones as a potential risk factor for hypospadias has been widely studied. Waste areas are suspected areas of risk [Dolk et al., 1998], especially since the PCB levels in maternal serum of children with hypospadias are higher, although not significantly so. An increased concentration of hexachlorobenzene (HCB) may be associated [Giordano et al., 2010], although this has not been confirmed by other studies [Rignell-Hydbom et al., 2012]. The prevalence of hypospadias also appears to be higher in areas of intensive agriculture with pesticide use [Morera et al., 2006]. A French longitudinal study explored the effects of soil contamination with a $1-\mathrm{km}$ resolution and domestic use of pesticides. Domestic pesticide use for fleas and ticks was associated with hypospadias but not with crop acreage [Cognez et al., 2019]. We found that industrial plants, incinerators, and waste areas were more frequently present within a $3-\mathrm{km}$ radius of the homes of hypospadiac children than of controls, but the agricultural area did not reach significance [Kalfa et al., 2015]. An increase in the number of hypospadias cases was reported in parents exposed to dioxin after the Seveso accident [Mastroiacovo et al., 1988]. Finally, seasonal variations in hypospadias are suspected [Jin et al., 2010].

\section{Hypospadias, Occupational Exposure, and}

\section{Cumulative Effects of Multiple Exposures}

In addition to direct measurement of EDCs, questionnaires on occupational exposure help to assess the environmental risk. In 2 studies, we found that maternal work related to agriculture increased the risk of hypospadias [Sun et al., 2009; Dugas et al., 2010]. Other suspected activities include leather work [Garcia and Fletcher, 1998], hairdressing [Ormond et al., 2009; Haraux et al., 2016], automobile repair [Irgens et al., 2000], and jobs where metal dust is produced [Brouwers et al., 2010]. Most studies focused on a limited number of substances, were ret- rospective, and were sometimes based on data banks with limited clinical details and/or a wide variability in phenotypes and nonhomogeneous cohorts. We conducted a multicenter prospective phenotype-specific study to explore all potential sources of exposure in patients with strictly isolated hypospadias, after first excluding the most frequent genetic defects [Kalfa et al., 2015]. We found that fetal exposure to EDCs was a significant risk factor for hypospadias in our series (OR 3.8). The types of substance having an impact on the phenotype were heterogeneous, but detergents, pesticides, and cosmetics accounted for $75 \%$ of the cases, with a possible cumulative effect of various substances. Maternal exposure was the most significant, especially among cleaners, hairdressers, beauticians, and laboratory workers. The fathers' occupational exposure during the periconceptional period was also significant, mainly for agricultural workers, laboratory technicians, mechanics, and painters. The effects of a mixture of EDCs, as described in animal models with disruption of AR translocation and activation [McComb et al., 2019], may be more harmful than a single high-dose exposure, recapitulating the cocktail effects of EDCs.

\section{Hypospadias and Atmospheric Pollution and Conditions}

More recently, atmospheric pollution and conditions have been suspected of participating in the occurrence of hypospadias. There is a growing number of reports on the association between air pollution and congenital anomalies. Salavati et al. [2018] conducted a case-control study on about 7,500 subjects through the EUROCAT register and identified an association between air pollutants (nitrogen dioxide: $\mathrm{NO}_{2}$, and PM10 and PM2.5) and genital defects, mainly hypospadias. Another study in Taiwan based on 200 hypospadiac boys and 2,000 random controls showed that PM2.5 exposure during the first trimester and exposure to ozone $\left(\mathrm{O}_{3}\right)$ during the first month of pregnancy were associated with a higher incidence of hypospadias [Huang et al., 2020]. Limitations included register-based phenotypes, limited data regarding familial history and occupational exposure, and possible moves during gestation. A systematic review based on 9 studies suggested a modest association between prenatal exposure to PM2.5 in the month before pregnancy or the first trimester and the risk of hypospadias in offspring. The pooled RR was 1.17 (95\% CI, 1.00-1.36) [Lin et al., 2021]. Heavy metal hazardous air pollutants (HMHAP) are also potential EDCs and hypospadias inducers. Based on 8,900 cases of hypospadias obtained from the Texas Birth Defects Registry, a case-control study found an associa- 
tion between HMHAP exposure and hypospadias. Cadmium, mercury, nickel, arsenic, and chromium showed associations with different schemes of risk association depending on the substance [White et al., 2019]. Altitude may play a role in the distribution of some congenital defects [Lopez-Camelo and Orioli, 1996; Poletta et al., 2007]. One study analyzed the spatiotemporal repartition of hypospadias clusters in South America and found that living above 2,000 $\mathrm{m}$ has a protective effect [Fernandez et al., 2016b]. Whereas hypobaric hypoxia is associated with the development of congenital anomalies, other factors such as diet, reduced exposure to EDCs, or the low genetic susceptibility of some ethnic groups may explain the results. Higher ambient temperature has also been studied [Kilinc et al., 2016].

\section{Meta-Analyses and Systematic Reviews}

Systematic reviews and meta-analyses provide less clear results. Bonde et al. [2016] took into account the studies of 28 populations and reported an overall OR close to $1(1.13,95 \% \mathrm{CI}, 0.86-1.50)$. The results were globally the same, both for all substances together and specific substances, but the OR was slightly elevated for one compound: p,p'-DDE. Data on specific exposures and hypospadias only were limited. Overall, this meta-analysis showed a small increased risk of male reproductive disorder after prenatal exposure to EDCs. Another critical review [Foster et al., 2017], covering 2003-2014, reported a strong association between congenital defects and parental occupation, but direct measures of the substances were lacking to confirm the hypothesis. A systematic review in Brazil, which has heavy pesticide use, was only able to find a few studies on the effects of these substances on children's health, and the study designs often prevented conclusions from being drawn on reproductive defects [Froes Asmus et al., 2016].

\section{EDCs and Micropenis}

Several studies on the relationship between hypospadias and EDCs have included micropenis but reported results on genital defects as a single entity. However, the literature specifically addressing micropenis or stratifying the results according to specific phenotypes is less abundant than for hypospadias.

A 16-months nested case-controlled study we conducted in a large population in southern France evidenced a $0.35 \%$ prevalence of micropenis [Gaspari et al., 2011a], which is about 23-times the rate shown by an ep- idemiological study conducted between 1997 and 2000 in the USA [Nelson et al., 2005] and more than 5-times the prevalence reported by Mazen et al. [2010]. We observed that the self-reported occupational pesticide exposure of both parents was a significant risk factor for male genital malformations (OR 4.41; 95\% CI, 1.21-16.00). We also conducted a 24-months study in an intensive pesticideuse area in northeastern Brazil and reported severe micropenis (-4 SD) in $0.66 \%$ of the population, which is interestingly almost twice the rate we found in southern France [Gaspari et al., 2012]. Poor living conditions (favelas), resulting in widespread and frequent use of residential DTT and maternal occupational exposure to EDCs, were identified as the major risk factors. All newborns with micropenis had normal plasma testosterone and no $A R$ mutation, and only 2 A49T polymorphisms of $5 a \mathrm{R}$ were identified [Gaspari et al., 2012]. Another study in southern Spain focused on intensive agriculture with high pesticide use and identified an increased risk of micropenis in this area. The association was less strong than for hypospadias and the CI of the OR was large [Garcia et al., 2017]. In an Egyptian population, mean penile length showed a linear relationship with free testosterone and was lower in neonates exposed to EDCs [El Kholy et al., 2013]. A Japanese study evaluated the polymorphism of aryl hydrocarbon receptor repressor (AHRR) involved in the dioxin signaling pathway as a risk factor for micropenis [Soneda et al., 2005]. Dioxin is known to exert deleterious effects on the male reproductive system [Poland and Knutson, 1982] and AHRR induces a negative feedback loop in the dioxin-related signal transduction pathway. Based on a series of 73 boys with micropenis, the authors identified an at-risk genotype. None of the cited studies included the direct measurement of EDCs in the patients or controlled for confounding factors. Since environmental pollutants are known for their estrogenic activity, we detected their presence by measuring the estrogenic bioactivity in males with defective genital development including micropenis, using an ultrasensitive cell bioassay with transfected cells for the human ER [Paris et al., 2006; Gaspari et al., 2011b].

\section{Transgenerational Effects of EDCs}

The medical scandal of diethylstilbestrol (DES) strengthened the concepts of EDCs and the fetal basis for adult disease [Newbold, 2004]. More recently, authors have reported that the adverse effects of DES are transmitted to subsequent generations in animal models 
[Walker and Kurth, 1995; Newbold et al., 1998, 2000, 2006; Skinner, 2007]. DES is a synthetic nonsteroidal estrogen that was first produced for hormonal therapy in 1938 and then prescribed to pregnant women to prevent potential miscarriages and premature delivery by acting as an estrogen analog [IARC Working Group on the Evaluation of Carcinogenic Risks to Humans, 2012]. Unfortunately, it was found to be not only ineffective but also harmful. Although the molecular basis for DES action is not fully understood, it seems to involve ERs other than $\mathrm{ER} \alpha$, such as the estrogen-related receptors (ERRs) [Greschik et al., 2004] or the orphan nuclear receptor NROb-2 [Volle et al., 2009]. Moreover, DES also presents antiandrogenic activity by competing with natural androgens for the ligand-binding domain of the AR [McKinnell et al., 2001].

DES illustrates the effects of EDCs on genital development [Newbold, 2004]. Klip et al. [2002] reported an increased risk of hypospadias in the sons of DES daughters from a cohort of women diagnosed with fertility problems. Brouwers et al., [2010] found that pregnant women who were DES daughters were at risk of giving birth to hypospadiac boys, as did other authors [Pons et al., 2005]. In contrast, another study found no increased risk of penile defect with a 1.7 OR (95\% CI, 0.4-6.8) for the risk of hypospadias. A cohort study conducted in collaboration with a French association of DES-treated women found an increased risk of hypospadias in both fetuses exposed to DES and their descendance. The prevalence of hypospadias was low in boys unexposed to DES in utero, whereas it was high in the in utero-exposed boys $(3.57 \%$, $p=0.02)$. In the following generation, the prevalence of hypospadias in boys born to DES daughters was high when compared with boys born to unexposed parents $(8.2 \%, n=8 / 97$ vs. $n=0 / 360 ; p<0.001)$. Changes in epigenetic background and alteration of DNA methylation are highly suspected [Walker and Kurth, 1995; GuerreroBosagna et al., 2012]. The association between hypospadias in grandsons and uterine abnormalities in their mothers also suggests the role of placental insufficiency for the transgenerational effect of DES. Over the past 10 years, we have analyzed almost 2,000 DNAs from undervirilized XY children or adults with normal/high plasma testosterone concentration, as part of a national collaborative program on the molecular genetics of XY DSD. We recently reported that 11 of these DNAs were extracted from the sons of women who had been exposed in utero to DES, supporting the hypothesis that DES also harms the third generation [Gaspari et al., 2021a]. Indeed, we also recently presented an 8-year-old girl with cervical
CCAC, whose grandmother had received DES therapy during pregnancy with the patient's mother [Gaspari et al., 2021b]. Although no direct causal link was demonstrated, this case raises for the first time the hypothesis of multigenerational effects of DES in girls and strongly suggests the need to follow the granddaughters of DES-treated women.

\section{Differential Effects of EDCs on Genital Development}

It is noteworthy that similar substances can induce hypospadias, micropenis, or combined phenotypes. Temporal windows of sensitivity, tissue-specific action, or particular downstream targets of the androgen signaling pathway may explain this differential effect. Zhenget al. [2015], using flutamide and tamoxifen administration, showed that an early action may induce ambiguous genitalia, disruption during the narrow window of urethral development is associated with hypospadias, and a later effect of EDCs at the time of penile growth results in micropenis. In addition to showing that the stage of disruption of androgen signaling determines the class of penile defect, the authors demonstrated that the intensity of disruption affects genital development in a dosedependent manner and that an estrogen-responsive phase of penile development regulates apoptosis and proliferation.

\section{Conclusion}

Disorders of penile development that include hypospadias and micropenis are among the most frequent male birth defects worldwide. Although many questions about the increased incidence of hypospadias remain unresolved, the impact of fetal exposure to EDCs in the development of male penile disorders is now indisputable. This review summarizes the growing body of epidemiological, clinical, and experimental studies that clearly show evidence of the impact of EDC exposure on penile development. Moreover, large epidemiological studies and studies on animals exposed in utero to DES and other EDCs have provide data that point toward the epigenetic effects of utero exposure to EDCs that may be passed on to future generations. Although these epigenetic mechanisms have not been fully elucidated in humans, the precautionary principle should be applied in order to protect these future generations. 


\section{Conflict of Interest Statement}

The authors have no conflicts of interest to declare.

\section{Author Contributions}

N.K.: conceptualization, literature search, writing of the original draft. L.G.: literature search, writing of theoriginal draft. B.T.: literature search, writing of the original draft. F.P.: manuscript reading and improvement. A.B.: manuscript reading and improvement. S.H.: manuscript reading and improvement. C.S.: manuscript reading and improvement.

\section{References}

Abdel-Maksoud FM, Ali FAZ, Akingbemi BT Prenatal exposures to bisphenol A and di (2-ethylhexyl) phthalate disrupted seminiferous tubular development in growing male rats. Reprod Toxicol. 2019;88:85-90.

Acconcia F, Pallottini V, Marino M. Molecular mechanisms of action of BPA. Dose Response. 2015;13:1559325815610582.

Adibi JJ, Whyatt RM, Hauser R, Bhat HK, Davis BJ, Calafat AM, et al. Transcriptional biomarkers of steroidogenesis and trophoblast differentiation in the placenta in relation to prenatal phthalate exposure. Environ Health Perspect. 2010;118:291-6.

Agopian AJ, Lupo PJ, Canfield MA, Langlois PH. Case-control study of maternal residential atrazine exposure and male genital malformations. Am J Med Genet A. 2013;161 A:977-82.

Akre O, Lipworth L, Cnattingius S, Sparén P, Ekbom A. Risk factor patterns for cryptorchidism and hypospadias. Epidemiology. 1999; 10:364-9.

Akre O, Boyd HA, Ahlgren M, Wilbrand K, Westergaard T, Hjalgrim $\mathrm{H}$, et al. Maternal and gestational risk factors for hypospadias. Environ Health Perspect. 2008;116:1071-6.

Annamalai J, Namasivayam V. Endocrine disrupting chemicals in the atmosphere: Their effects on humans and wildlife. Environ Int. 2015;76:78-97.

Arcaro KF, O'Keefe PW, Yang Y, Clayton W, Gierthy JF. Antiestrogenicity of environmental polycyclic aromatic hydrocarbons in human breast cancer cells. Toxicology. 1999;133: $115-27$.

Aschengrau A, Gallagher LG, Winter M, Butler L, Patricia Fabian M, Vieira VM. Modeled exposure to tetrachloroethylene-contaminated drinking water and the occurrence of birth defects: a case-control study from Massachusetts and Rhode Island. Environ Health. 2018; 17:58.

Baskin LS, Himes K, Colborn T. Hypospadias and endocrine disruption: is there a connection? Environ Health Perspect. 2001;109:1175-83.

Baskin L, Shen J, Sinclair A, Cao M, Liu X, Liu G, et al. Development of the human penis and clitoris. Differentiation. 2018;103:74-85.

Benassou I. Effet des pesticides MCPA et imidaclopride sur la régulation des voies de signalisation du récepteur à la dioxine (AHR) et au récepteur aux androgènes $(\mathrm{AR})$. Université de Sherbrooke; 2016.
Benjamin S, Pradeep S, Josh MS, Kumar S, Masai E. A monograph on the remediation of hazardous phthalates. J Hazard Mater. 2015;298:58-72.

Boisen KA, Chellakooty M, Schmidt IM, Kai CM, Damgaard IN, Suomi AM, et al. Hypospadias in a cohort of 1072 Danish newborn boys: prevalence and relationship to placental weight, anthropometrical measurements at birth, and reproductive hormone levels at three months of age. J Clin Endocrinol Metab. 2005;90:4041-6.

Bonde JP, Flachs EM, Rimborg S, Glazer CH, Giwercman A, Ramlau-Hansen $\mathrm{CH}$, et al. The epidemiologic evidence linking prenatal and postnatal exposure to endocrine disrupting chemicals with male reproductive disorders: a systematic review and meta-analysis. Hum Reprod Update. 2016;23:104-25.

Brehm E, Flaws JA. Transgenerational effects of endocrine-disrupting chemicals on male and female reproduction. Endocrinology. 2019; 160:1421-35.

Brock JW, Melnyk LJ, Caudill SP, Needham LL, Bond AE. Serum levels of several organochlorine pesticides in farmers correspond with dietary exposure and local use history. Toxicol Ind Health. 1998;14:275-89.

Brouwers MM, Feitz WF, Roelofs LA, Kiemeney LA, de Gier RP, Roeleveld N. Risk factors for hypospadias. Eur J Pediatr. 2007;166:671-8.

Brouwers MM, van der Zanden LF, de Gier RP, Barten EJ, Zielhuis GA, Feitz WF, et al. Hypospadias: risk factor patterns and different phenotypes. BJU Int. 2010;105:254-62.

Bruner-Tran KL, Gnecco J, Ding T, Glore DR, Pensabene V, Osteen KG. Exposure to the environmental endocrine disruptor TCDD and human reproductive dysfunction: Translating lessons from murine models. Reprod Toxicol. 2017;68:59-71.

Canon S, Mosley B, Chipollini J, Purifoy JA, Hobbs C. Epidemiological assessment of hypospadias by degree of severity. J Urol. 2012; 188:2362-6.

Carmichael SL, Shaw GM, Nelson V, Selvin S, Torfs CP, Curry CJ. Hypospadias in California: trends and descriptive epidemiology. Epidemiology. 2003;14:701-6.

Carmichael SL, Herring AH, Sjödin A, Jones R, Needham L, Ma C, et al. Hypospadias and halogenated organic pollutant levels in maternal mid-pregnancy serum samples. Chemosphere. 2010;80:641-6.
Carmichael SL, Yang W, Roberts EM, Kegley SE, Wolff C, Guo L, et al. Hypospadias and residential proximity to pesticide applications. Pediatrics. 2013;132:e1216-26.

Chambers CD, Castilla EE, Orioli I, Jones KL. Intrauterine growth restriction in like-sex twins discordant for structural defects. Birth Defects Res Part A Clin Mol Teratol. 2006;76: 246-8.

Chen T, Li Q, Xu J, Ding K, Wang Y, Wang W, et al. Mutation screening of BMP4, BMP7, HOXA4 and HOXB6 genes in Chinese patients with hypospadias. Eur J Hum Genet. 2007; 15:23-8.

Chevalier N, Bouskine A, Fenichel P. Bisphenol A promotes testicular seminoma cell proliferation through GPER/GPR30. Int J Cancer. 2012;130:241-2.

Chevrier C, Petit C, Philippat C, Mortamais M, Slama R, Rouget F, et al. Maternal urinary phthalates and phenols and male genital anomalies. Epidemiology. 2012;23:353-6.

Choi H, Kim J, Im Y, Lee S, Kim Y. The association between some endocrine disruptors and hypospadias in biological samples. J Environ Sci Health A Tox Hazard Subst Environ Eng. 2012;47:2173-9.

Christensen JS, Asklund C, Skakkebæk NE, Jørgensen N, Andersen HR, Jørgensen TM, et al. Association between organic dietary choice during pregnancy and hypospadias in offspring: a study of mothers of 306 boys operated on for hypospadias. J Urol. 2013;189: 1077-82.

Clausen I, Kietz S, Fischer B. Lineage-specific effects of polychlorinated biphenyls (PCB) on gene expression in the rabbit blastocyst. Reprod Toxicol. 2005;20:47-56.

Cognez N, Warembourg C, Zaros C, Metten MA, Bouvier G, Garlantézec R, et al. Residential sources of pesticide exposure during pregnancy and the risks of hypospadias and cryptorchidism: the French ELFE birth cohort. Occup Environ Med. 2019;76:672-9.

Crescioli C, Maggi M, Vannelli GB, Ferruzzi P, Granchi S, Mancina R, et al. Expression of functional estrogen receptors in human fetal male external genitalia. J Clin Endocrinol Metab. 2003;88:1815-24.

Croft B, Ohnesorg T, Hewitt J, Bowles J, Quinn A, Tan J, et al. Human sex reversal is caused by duplication or deletion of core enhancers upstream of SOX9. Nat Commun. 2018;9:5319. 
Czubacka E, Czerczak S, Kupczewska-Dobecka MM. The overview of current evidence on the reproductive toxicity of dibutyl phthalate. Int J Occup Med Environ Health. 2020.

Deng C, Dai R, Li X, Liu F. Association between SNP12 in estrogen receptor alpha gene and hypospadias: a systematic review and metaanalysis. Springerplus. 2016;5:587.

Diamanti-Kandarakis E, Bourguignon JP, Giudice LC, Hauser R, Prins GS, Soto AM, et al. Endocrine-disrupting chemicals: an Endocrine Society scientific statement. Endocr Rev. 2009;30:293-342.

Dobrzynska MM. Phthalates - widespread occurrence and the effect on male gametes. Part 2. The effects of phthalates on male gametes and on the offspring. Rocz Panstw Zakl Hig. 2016; 67:209-21.

Dolk H, Vrijheid M, Armstrong B, Abramsky L, Bianchi F, Garne E, et al. Risk of congenital anomalies near hazardous-waste landfill sites in Europe: the EUROHAZCON study. Lancet. 1998;352:423-7.

Dolk H, Vrijheid M, Scott JE, Addor MC, Botting $\mathrm{B}$, de Vigan C, et al. Toward the effective surveillance of hypospadias. Environ Health Perspect. 2004;112:398-402.

Dugas J, Nieuwenhuijsen MJ, Martinez D, Iszatt $\mathrm{N}$, Nelson P, Elliott P. Use of biocides and insect repellents and risk of hypospadias. Occup Environ Med. 2010;67:196-200.

Ea V, Bergougnoux A, Philibert P, Servant-Fauconnet N, Faure A, Breaud J, et al. How far should we explore hypospadias? Next-generation sequencing applied to a large cohort of hypospadiac patients. Eur Urol. 2021;79:50715.

Earls AO, Axford IP, Braybrook JH. Gas chromatography-mass spectrometry determination of the migration of phthalate plasticisers from polyvinyl chloride toys and childcare articles. J Chromatogr A. 2003;983:237-46.

Edmonds LD, Layde PM, James LM, Flynt JW, Erickson JD, Oakley GP Jr. Congenital malformations surveillance: two American systems. Int J Epidemiol. 1981;10:247-52.

El Kholy M, Hamza RT, Saleh M, Elsedfy H. Penile length and genital anomalies in Egyptian male newborns: epidemiology and influence of endocrine disruptors. J Pediatr Endocrinol Metab. 2013;26:509-13.

EFSA Panel on Contaminants in the Food Chain (CONTAM), Knutsen HK, Alexander J, Barregård L, Bignami $\mathrm{M}$, Brüschweiler $\mathrm{B}$, et al. Risk for animal and human health related to the presence of dioxins and dioxin-like PCBs in feed and food. EFSA J. 2018;16:e05333.

Esser C, Steinwachs S, Herder C, Majora M, Lai ZW. Effects of a single dose of 2,3,7,8-tetrachlorodibenzo-p-dioxin, given at post-puberty, in senescent mice. Toxicol Lett. 2005;157: $89-98$.

Esteban M, Castaño A. Non-invasive matrices in human biomonitoring: a review. Environ Int. 2009;35:438-49.
EUROCAT. An Assessment and Analysis of Surveillance Data on Hypospadias in Europe. 2003. Available at: https://eu-rd-platform.jrc. ec.europa.eu/sites/default/files/eurocat-pubdocs/Special-Report-Hypospadias.pdf.

Fernandez MF, Arrebola JP, Jimenez-Diaz I, Saenz JM, Molina-Molina JM, Ballesteros O, et al. Bisphenol A and other phenols in human placenta from children with cryptorchidism or hypospadias. Reprod Toxicol. 2016a; 59:89-95.

Fernandez N, Lorenzo A, Bägli D, Zarante I. Altitude as a risk factor for the development of hypospadias. Geographical cluster distribution analysis in South America. J Pediatr Urol. 2016b;12:307.e1-307.e5.

Fisch H, Lambert SM, Hensle TW, Hyun G. Hypospadias rates in New York state are not increasing. J Urol. 2009;181:2291-4.

Fisher JS, Macpherson S, Marchetti N, Sharpe RM. Human 'testicular dysgenesis syndrome': a possible model using in-utero exposure of the rat to dibutyl phthalate. Hum Reprod. 2003;18:1383-94.

Flores-Luevano S, Farias P, Hernandez M, Romano-Riquer P, Weber JP, Dewailly E, et al. [DDT/DDE concentrations and risk of hypospadias. Pilot case-control study]. Salud Publica Mex. 2003;45:431-8.

Foster WG, Evans JA, Little J, Arbour L, Moore A, Sauve R, et al. Human exposure to environmental contaminants and congenital anomalies: a critical review. Crit Rev Toxicol. 2017; 47:59-84.

Frisbee SJ, Brooks AP Jr., Maher A, Flensborg P, Arnold S, Fletcher T, et al. The C8 health project: design, methods, and participants. Environ Health Perspect. 2009;117:1873-82.

Froes Asmus CI, Camara VM, Landrigan PJ, Claudio L. A Systematic review of children's environmental health in Brazil. Ann Glob Health. 2016;82:132-48.

Gao J, Wang K, Wang Y, Liu S, Zhu C, Hao J, et al. Temporal-spatial characteristics and source apportionment of PM2.5 as well as its associated chemical species in the BeijingTianjin-Hebei region of China. Environ Pollut. 2018;233:714-24.

Garcia AM, Fletcher T. Maternal occupation in the leather industry and selected congenital malformations. Occup Environ Med. 1998; 55:284-6.

Garcia J, Ventura MI, Requena M, Hernandez AF, Parron T, Alarcon R. Association of reproductive disorders and male congenital anomalies with environmental exposure to endocrine active pesticides. Reprod Toxicol. 2017; 71:95-100.

Garry VF, Schreinemachers D, Harkins ME, Griffith J. Pesticide appliers, biocides, and birth defects in rural Minnesota. Environ Health Perspect. 1996;104:394-9.

Gasnier C, Dumont C, Benachour N, Clair E, Chagnon MC, Séralini GE. Glyphosate-based herbicides are toxic and endocrine disruptors in human cell lines. Toxicology. 2009;262: $184-91$.
Gaspari L, Paris F, Jandel C, Kalfa N, Orsini M, Daurès JP, et al. Prenatal environmental risk factors for genital malformations in a population of 1442 French male newborns: a nested case-control study. Hum Reprod. 2011a;26: 3155-62.

Gaspari L, Paris F, Philibert P, Audran F, Orsini $\mathrm{M}$, Servant N, et al. 'Idiopathic' partial androgen insensitivity syndrome in 28 newborn and infant males: impact of prenatal exposure to environmental endocrine disruptor chemicals? Eur J Endocrinol. 2011b;165:579-87.

Gaspari L, Sampaio DR, Paris F, Audran F, Orsini $\mathrm{M}$, Neto JB, et al. High prevalence of micropenis in 2710 male newborns from an intensive-use pesticide area of Northeastern Brazil. Int J Androl. 2012;35:253-64.

Gaspari L, Paris F, Soyer-Gobillard MO, Hamamah S, Kalfa N, Sultan C. "Idiopathic" partial androgen insensitivity syndrome in 11 grandsons of women treated by diethylstilbestrol during gestation: a multi-generational impact of endocrine disruptor contamination? J Endocrinol Invest. 2021a;44:379-81.

Gaspari L, Paris F, Cassel-Knipping N, Villeret J, Verschuur A, Soyer-Gobillard MO, et al. Diethylstilbestrol exposure during pregnancy with primary clear cell carcinoma of the cervix in an 8-year-old granddaughter: a multigenerational effect of endocrine disruptors? Hum Reprod. 2021b;36(1):82-6.

Georgescu B, Georgescu C, Dărăban S, Bouaru A, Paşcalău S. Heavy metals acting as endocrine disrupters. Anim Sci Biotechnol. 2011;44:8993.

Ghirri P, Scaramuzzo RT, Bertelloni S, Pardi D, Celandroni A, Cocchi G, et al. Prevalence of hypospadias in Italy according to severity, gestational age and birthweight: an epidemiological study. Ital J Pediatr. 2009;35:18.

Giordano F, Carbone P, Nori F, Mantovani A, Taruscio D, Figà-Talamanca I. Maternal diet and the risk of hypospadias and cryptorchidism in the offspring. Paediatr Perinat Epidemiol. 2008;22:249-60.

Giordano F, Abballe A, De Felip E, di Domenico A, Ferro F, Grammatico P, et al. Maternal exposures to endocrine disrupting chemicals and hypospadias in offspring. Birth Defects Res A Clin Mol Teratol. 2010;88:241-50.

Gray LE Jr., Kelce WR. Latent effects of pesticides and toxic substances on sexual differentiation of rodents. Toxicol Ind Health. 1996;12:51531.

Gray LE, Ostby J, Furr J, Wolf CJ, Lambright C, Parks L, et al. Effects of environmental antiandrogens on reproductive development in experimental animals. Hum Reprod Update. 2001;7:248-64.

Greschik H, Flaig R, Renaud JP, Moras D. Structural basis for the deactivation of the estrogen-related receptor gamma by diethylstilbestrol or 4-hydroxytamoxifen and determinants of selectivity. J Biol Chem. 2004;279: 33639-46. 
Guerrero-Bosagna C, Covert TR, Haque MM, Settles M, Nilsson EE, Anway MD, et al. Epigenetic transgenerational inheritance of vinclozolin induced mouse adult onset disease and associated sperm epigenome biomarkers. Reprod Toxicol. 2012;34:694-707.

Guillette LJ Jr. Endocrine disrupting contaminants - beyond the dogma. Environ Health Perspect. 2006;114(Suppl 1):9-12.

Hamers T, Kamstra JH, Sonneveld E, Murk AJ, Kester MH, Andersson PL, et al. In vitro profiling of the endocrine-disrupting potency of brominated flame retardants. Toxicol Sci. 2006;92:157-73.

Haraux E, Braun K, Buisson P, Stéphan-Blanchard E, Devauchelle C, Ricard J, et al. Maternal exposure to domestic hair cosmetics and occupational endocrine disruptors is associated with a higher risk of hypospadias in the offspring. Int J Environ Res Public Health. 2016; 14(1).

Haraux E, Tourneux P, Kouakam C, StephanBlanchard E, Boudailliez B, Leke A, et al. Isolated hypospadias: The impact of prenatal exposure to pesticides, as determined by meconium analysis. Environ Int. 2018;119:20-5.

Harrad S, Wang Y, Sandaradura S, Leeds A. Human dietary intake and excretion of dioxinlike compounds. J Environ Monit. 2003;5: 224-8.

Hayes TB, Collins A, Lee M, Mendoza M, Noriega $\mathrm{N}$, Stuart AA, et al. Hermaphroditic, demasculinized frogs after exposure to the herbicide atrazine at low ecologically relevant doses. Proc Natl Acad Sci USA. 2002;99:5476-80.

Hites RA. Polybrominated diphenyl ethers in the environment and in people: a meta-analysis of concentrations. Environ Sci Technol. 2004; 38:945-56.

Hlisnikova H, Petrovicova I, Kolena B, Sidlovska M, Sirotkin A. Effects and mechanisms of phthalates' action on reproductive processes and reproductive health: A literature review. Int J Environ Res Public Health. 2020;17: 6811.

Hu XJ, Song WR, Gao LY, Nie SP, Eisenbrand G, Xie MY. Assessment of dietary phytoestrogen intake via plant-derived foods in China. Food Addit Contam Part A Chem Anal Control Expo Risk Assess. 2014;31:1325-35.

Huang X, Cang X, Liu J. Molecular mechanism of Bisphenol A on androgen receptor antagonism. Toxicol In Vitro. 2019;61:104621.

Huang CC, Pan SC, Chen BY, Guo YL. Periconceptional exposure to air pollution and congenital hypospadias among full-term infants. Environ Res. 2020;183:109151.

Hughes IA, Northstone K, Golding J, Team AS. Reduced birth weight in boys with hypospadias: an index of androgen dysfunction? Arch Dis Child Fetal Neonatal Ed. 2002;87:F150-1.

Irgens A, Krüger K, Skorve AH, Irgens LM. Birth defects and paternal occupational exposure. Hypotheses tested in a record linkage based dataset. Acta Obstet Gynecol Scand. 2000;79: $465-70$.
Iszatt N, Nieuwenhuijsen MJ, Nelson P, Elliott P, Toledano MB. Water consumption and use, trihalomethane exposure, and the risk of hypospadias. Pediatrics. 2011;127:e389-97.

Ivell R, Hartung S. The molecular basis of cryptorchidism. Mol Hum Reprod. 2003;9:175-81.

IARC Working Group on the Evaluation of Carcinogenic Risks to Humans. Pharmaceuticals. Volume 100 A. A review of human carcinogens. IARC Monogr Eval Carcinog Risks Hum. 2012;100:1-401.

Jensen MS, Anand-Ivell R, Nørgaard-Pedersen B, Jönsson BA, Bonde JP, Hougaard DM, et al. Amniotic fluid phthalate levels and male fetal gonad function. Epidemiology. 2015;26:91-9.

Jin L, Ye R, Zheng J, Hong S, Ren A. Secular trends of hypospadias prevalence and factors associated with it in southeast China during 19932005. Birth Defects Res A Clin Mol Teratol. 2010;88:458-65.

Kalfa N, Paris F, Philibert P, Orsini M, Broussous $\mathrm{S}$, Fauconnet-Servant $\mathrm{N}$, et al. Is hypospadias associated with prenatal exposure to endocrine disruptors? A french collaborative controlled study of a cohort of 300 consecutive children without genetic defect. Eur Urol. 2015;68:1023-30.

Kalfa N, Gaspari L, Ollivier M, Philibert P, Bergougnoux A, Paris F, et al. Molecular genetics of hypospadias and cryptorchidism recent developments. Clin Genet. 2019;95:122-31.

Kelce WR, Stone CR, Laws SC, Gray LE, Kemppainen JA, Wilson EM. Persistent DDT metabolite $\mathrm{p}, \mathrm{p}^{\prime}$-DDE is a potent androgen receptor antagonist. Nature. 1995;375:581-5.

Kilinc MF, Cakmak S, Demir DO, Doluoglu OG, Yildiz Y, Horasanli K, et al. Does maternal exposure during pregnancy to higher ambient temperature increase the risk of hypospadias?. J Pediatr Urol. 2016;12:407-e6.

Kitamura S, Suzuki T, Sanoh S, Kohta R, Jinno N, Sugihara K, et al. Comparative study of the endocrine-disrupting activity of bisphenol A and 19 related compounds. Toxicol Sci. 2005; 84:249-59.

Klip H, Verloop J, van Gool JD, Koster ME, Burger CW, van Leeuwen FE, et al. Hypospadias in sons of women exposed to diethylstilbestrol in utero: a cohort study. Lancet. 2002;359: $1102-7$.

Knez J. Endocrine-disrupting chemicals and male reproductive health. Reprod Biomed Online. 2013;26:440-8.

Kniewald J, Osredecki V, Gojmerac T, Zechner V, Kniewald Z. Effect of s-triazine compounds on testosterone metabolism in the rat prostate. J Appl Toxicol. 1995;15:215-8.

Koniecki D, Wang R, Moody RP, Zhu J. Phthalates in cosmetic and personal care products: concentrations and possible dermal exposure. Environ Res. 2011;111:329-36.

Koren G, Carnevale A, Ling J, Ozsarfati J, Kapur B, Bagli D. Fetal exposure to polybrominated diphenyl ethers and the risk of hypospadias: focus on the congeners involved. J Pediatr Urol. 2019;15:405-e6.
Kristensen P, Irgens LM, Andersen A, Bye AS, Sundheim L. Birth defects among offspring of Norwegian farmers, 1967-1991. Epidemiology. 1967-19911997;8:537-44.

Lara NLM, van den Driesche S, Macpherson S, França LR, Sharpe RM. Dibutyl phthalate induced testicular dysgenesis originates after seminiferous cord formation in rats. Sci Rep. 2017;7:2521.

Lee LK, He J. Reductive debromination of polybrominated diphenyl ethers by anaerobic bacteria from soils and sediments. Appl Environ Microbiol. 2010;76:794-802.

Lin HC, Guo JM, Ge P, Ou P. Association between prenatal exposure to ambient particulate matter and risk of hypospadias in offspring: A systematic review and meta-analysis. Environ Res. 2021;192:110190.

Longnecker MP, Klebanoff MA, Brock JW, Zhou H, Gray KA, Needham LL, et al. Maternal serum level of 1,1-dichloro-2,2-bis(p-chlorophenyl)ethylene and risk of cryptorchidism, hypospadias, and polythelia among male offspring. Am J Epidemiol. 2002;155:313-22.

Lopez-Camelo JS, Orioli IM. Heterogeneous rates for birth defects in Latin America: hints on causality. Genet Epidemiol. 1996;13:469-81.

Luben TJ, Nuckols JR, Mosley BS, Hobbs C, Reif JS. Maternal exposure to water disinfection by-products during gestation and risk of hypospadias. Occup Environ Med. 2008;65: $420-9$.

Lyche JL, Rosseland C, Berge G, Polder A. Human health risk associated with brominated flameretardants (BFRs). Environ Int. 2015;74:17080.

Mai X, Dong Y, Xiang L, Er Z. Maternal exposure to 2,3,7,8-tetrachlorodibenzo-p-dioxin suppresses male reproductive functions in their adulthood. Hum Exp Toxicol. 2020;39:890905.

Malisch R, Kotz A. Dioxins and PCBs in feed and food - review from European perspective. Sci Total Environ. 2014;491-492:2-10.http:// dx.doi.org/10.1016/j.scitotenv.2014.03.022.

Marie C, Vendittelli F, Sauvant-Rochat MP. Obstetrical outcomes and biomarkers to assess exposure to phthalates: A review. Environ Int. 2015;83:116-36.

Martin MB, Reiter R, Johnson M, Shah MS, Iann MC, Singh B, et al. Effects of tobacco smoke condensate on estrogen receptor-alpha gene expression and activity. Endocrinology. 2007; 148:4676-86.

Mastroiacovo P, Spagnolo A, Marni E, Meazza L, Bertollini R, Segni G, et al. Birth defects in the Seveso area after TCDD contamination. JAMA. 1988;259:1668-72.

Mazen I, El-Ruby M, Kamal R, El-Nekhely I, ElGhandour M, Tantawy S, et al. Screening of genital anomalies in newborns and infants in two egyptian governorates. Horm Res Paediatr. 2010;73:438-42. 
McComb J, Mills IG, Muller M, Berntsen HF, Zimmer KE, Ropstad E, et al. Human bloodbased exposure levels of persistent organic pollutant (POP) mixtures antagonise androgen receptor transactivation and translocation. Environ Int. 2019;132:105083.

McGlynn KA, Guo X, Graubard BI, Brock JW, Klebanoff MA, Longnecker MP. Maternal pregnancy levels of polychlorinated biphenyls and risk of hypospadias and cryptorchidism in male offspring. Environ Health Perspect. 2009;117:1472-6.

McKinnell C, Atanassova N, Williams K, Fisher JS, Walker M, Turner KJ, et al. Suppression of androgen action and the induction of gross abnormalities of the reproductive tract in male rats treated neonatally with diethylstilbestrol. J Androl. 2001;22:323-38.

Meerts IA, Letcher RJ, Hoving S, Marsh G, Bergman A, Lemmen JG, et al. In vitro estrogenicity of polybrominated diphenyl ethers, hydroxylated PDBEs, and polybrominated bisphenol A compounds. Environ Health Perspect. 2001;109:399-407.

Michikawa T, Yamazaki S, Ono M, Kuroda T, Nakayama SF, Suda E, et al. Isoflavone intake in early pregnancy and hypospadias in the Japan Environment and Children's Study. Urology. 2019;124:229-36.

Morera AM, Valmalle AF, Asensio MJ, Chossegros L, Chauvin MA, Durand P, et al. A study of risk factors for hypospadias in the RhoneAlpes region (France). J Pediatr Urol. 2006;2: 169-77.

Morgan EA, Nguyen SB, Scott V, Stadler HS. Loss of Bmp7 and Fgf8 signaling in Hoxa13-mutant mice causes hypospadia. Development. 2003;130:3095-109.

Myatt L. Placental adaptive responses and fetal programming. J Physiol (Lond). 2006;572: 25-30.

Nadal M, Domingo JL. Sources of Human Exposure. In: Carpenter DO, editor. Effects of Persistent and Bioactive Organic Pollutants on Human Health. New York: Wiley and Sons; 2013. p. 8-25.

Nadal A, Fuentes E, Ripoll C, Villar-Pazos S, Castellano-Muñoz M, Soriano S, et al. Extranuclear-initiated estrogenic actions of endocrine disrupting chemicals: Is there toxicology beyond paracelsus? J Steroid Biochem Mol Biol. 2018;176:16-22.

Nassar N, Abeywardana P, Barker A, Bower C. Parental occupational exposure to potential endocrine disrupting chemicals and risk of hypospadias in infants. Occup Environ Med. 2010;67:585-9.

Nelson CP, Park JM, Wan J, Bloom DA, Dunn RL, Wei JT. The increasing incidence of congenital penile anomalies in the United States. J Urol. 2005;174:1573-6.

Nelson P, Nieuwenhuijsen M, Jensen TK, Mouriquand P, Hughes I, Wilcox D, et al. Prevalence of hypospadias in the same geographic region as ascertained by three different registries. Birth Defects Res Part A Clin Mol Teratol. 2007;79:685-7.
Newbold RR. Lessons learned from perinatal exposure to diethylstilbestrol. Toxicol Appl Pharmacol. 2004;199:142-50.

Newbold RR, Hanson RB, Jefferson WN, Bullock BC, Haseman J, McLachlan JA. Increased tumors but uncompromised fertility in the female descendants of mice exposed developmentally to diethylstilbestrol. Carcinogenesis. 1998; 19:1655-63.

Newbold RR, Hanson RB, Jefferson WN, Bullock BC, Haseman J, McLachlan JA. Proliferative lesions and reproductive tract tumors in male descendants of mice exposed developmentally to diethylstilbestrol. Carcinogenesis. 2000; 21:1355-63.

Newbold RR, Padilla-Banks E, Jefferson WN. Adverse effects of the model environmental estrogen diethylstilbestrol are transmitted to subsequent generations. Endocrinology. 2006;147:S11-7.

North K, Golding J. A maternal vegetarian diet in pregnancy is associated with hypospadias. The ALSPAC Study Team. Avon Longitudinal Study of Pregnancy and Childhood. BJU Int. 2000;85:107-13

Olea N, Olea-Serrano F, Lardelli-Claret P, Rivas A, Barba-Navarro A. Inadvertent exposure to xenoestrogens in children. Toxicol Ind Health. 1999;15:151-8.

Ormond G, Nieuwenhuijsen MJ, Nelson P, Toledano MB, Iszatt N, Geneletti S, et al. Endocrine disruptors in the workplace, hair spray, folate supplementation, and risk of hypospadias: case-control study. Environ Health Perspect. 2009;117:303-7.

Paris F, Balaguer P, Térouanne B, Servant N, Lacoste C, Cravedi JP, et al. Phenylphenols, biphenols, bisphenol-A and 4-tert-octylphenol exhibit alpha and beta estrogen activities and antiandrogen activity in reporter cell lines. Mol Cell Endocrinol. 2002;193:43-9.

Paris F, Jeandel C, Servant N, Sultan C. Increased serum estrogenic bioactivity in three male newborns with ambiguous genitalia: a potential consequence of prenatal exposure to environmental endocrine disruptors. Environ Res. 2006;100:39-43.

Paulozzi LJ. International trends in rates of hypospadias and cryptorchidism. Environ Health Perspect. 1999;107:297-302.

Paulozzi LJ, Erickson JD, Jackson RJ. Hypospadias trends in two US surveillance systems. Pediatrics. 1997;100:831-4.

Perez-Perez A, Maymo J, Duenas JL, Goberna R, Calvo JC, Varone C, et al. Leptin prevents apoptosis of trophoblastic cells by activation of MAPK pathway. Arch Biochem Biophys. 2008;477:390-5.

Petersen KU, Larsen JR, Deen L, Flachs EM, Hærvig KK, Hull SD, et al. Per- and polyfluoroalkyl substances and male reproductive health: a systematic review of the epidemiological evidence. J Toxicol Environ Health B Crit Rev. 2020;23:276-91
Pierik FH, Burdorf A, Deddens JA, Juttmann RE, Weber RF. Maternal and paternal risk factors for cryptorchidism and hypospadias: a casecontrol study in newborn boys. Environ Health Perspect. 2004;112:1570-6.

Poland A, Knutson JC. 2,3,7,8-tetrachlorodibenzo-p-dioxin and related halogenated aromatic hydrocarbons: examination of the mechanism of toxicity. Annu Rev Pharmacol Toxicol. 1982;22:517-54.

Poletta FA, Castilla EE, Orioli IM, Lopez-Camelo JS. Regional analysis on the occurrence of oral clefts in South America. Am J Med Genet A. 2007;143A:3216-27.

Pons JC, Papiernik E, Billon A, Hessabi M, Duyme M. Hypospadias in sons of women exposed to diethylstilbestrol in utero. Prenat Diagn. 2005;25:418-9.

Poon S, Koren G, Carnevale A, Aleksa K, Ling J, Ozsarfati J, et al. Association of in utero exposure to polybrominated diphenyl ethers with the risk of hypospadias. JAMA Pediatr. 2018; 172:851-6.

Porter MP, Faizan MK, Grady RW, Mueller BA. Hypospadias in Washington State: maternal risk factors and prevalence trends. Pediatrics. 2005; 115:e495-9.

Radke EG, Braun JM, Meeker JD, Cooper GS. Phthalate exposure and male reproductive outcomes: A systematic review of the human epidemiological evidence. Environ Int. 2018; 121(Pt 1):764-93.

Raghavan R, Romano ME, Karagas MR, Penna FJ. Pharmacologic and environmental endocrine disruptors in the pathogenesis of hypospadias: a review. Curr Environ Health Rep. 2018; 5:499-511.

Richard S, Moslemi S, Sipahutar H, Benachour N, Seralini GE. Differential effects of glyphosate and roundup on human placental cells and aromatase. Environ Health Perspect. 2005; 113:716-20.

Rignell-Hydbom A, Lindh CH, Dillner J, Jönsson BA, Rylander L. A nested case-control study of intrauterine exposure to persistent organochlorine pollutants and the risk of hypospadias. PLoS One. 2012;7:e44767.

Rochester JR, Bolden AL, Bisphenol S. F. Bisphenol S and F: A systematic review and comparison of the hormonal activity of bisphenol A substitutes. Environ Health Perspect. 2015; 123:643-50.

Rowdhwal SSS, Chen J. Toxic effects of di-2-ethylhexyl phthalate: An overview. Biomed Res Int. 2018;2018:1750368.

Safe S. Molecular biology of the Ah receptor and its role in carcinogenesis. Toxicol Lett. 2001; 120:1-7.

Salavati N, Strak M, Burgerhof JGM, de Walle HEK, Erwich JJHM, Bakker MK. The association of air pollution with congenital anomalies: An exploratory study in the northern Netherlands. Int J Hyg Environ Health. 2018; 221:1061-7. 
Sathyanarayana S, Butts S, Wang C, Barrett E, Nguyen R, Schwartz SM, et al. Early prenatal phthalate exposure, sex steroid hormones, and birth outcomes. J Clin Endocrinol Metab. 2017;102:1870-8.

Serrano T, Chevrier C, Multigner L, Cordier S, Jégou B. International geographic correlation study of the prevalence of disorders of male reproductive health. Hum Reprod. 2013;28: 1974-86.

Shafei A, Ramzy MM, Hegazy AI, Husseny AK, El-Hadary UG, Taha MM, et al. The molecular mechanisms of action of the endocrine disrupting chemical bisphenol $\mathrm{A}$ in the development of cancer. Gene. 2018;647:235-43.

Sharpe RM, Skakkebaek NE. Testicular dysgenesis syndrome: mechanistic insights and potential new downstream effects. Fertil Steril. 2008;89:e33-8.

Sheng Z, Wang C, Ren F, Liu Y, Zhu B. Molecular mechanism of endocrine-disruptive effects induced by Bisphenol A: The role of transmembrane G-protein estrogen receptor 1 and integrin av $\beta 3$. J Environ Sci (China). 2019;75: $1-13$.

Skakkebaek NE, Rajpert-De Meyts E, Main KM. Testicular dysgenesis syndrome: an increasingly common developmental disorder with environmental aspects. Hum Reprod. 2001; 16:972-8.

Skakkebaek NE, Rajpert-De Meyts E, Buck Louis GM, Toppari J, Andersson AM, Eisenberg ML, et al. Male reproductive disorders and fertility trends: Influences of environment and genetic susceptibility. Physiol Rev. 2016; 96:55-97.

Skinner MK. Endocrine disruptors and epigenetic transgenerational disease etiology. Pediatr Res. 2007;61:48R-50R.

Sonawane BR. Chemical contaminants in human milk: an overview. Environ Health Perspect. 1995;103(Suppl 6):197-205.

Soneda S, Fukami M, Fujimoto M, Hasegawa T, Koitabashi Y, Ogata T. Association of micropenis with Pro185Ala polymorphism of the gene for aryl hydrocarbon receptor repressor involved in dioxin signaling. Endocr J. 2005; 52:83-8.

Springer A, van den Heijkant M, Baumann S. Worldwide prevalence of hypospadias. J Pediatr Urol. 2016;12:152-7.

Stasenko S, Bradford EM, Piasek M, Henson MC, Varnai VM, Jurasović J, et al. Metals in human placenta: focus on the effects of cadmium on steroid hormones and leptin. J Appl Toxicol. 2010;30:242-53.

Stillwater BJ, Bull AC, Romagnolo DF, Neumayer LA, Donovan MG, Selmin OI. Bisphenols and risk of breast cancer: A narrative review of the impact of diet and bioactive food components. Front Nutr. 2020;7:581388

Stoll C, Alembik Y, Roth MP, Dott B. Genetic and environmental factors in hypospadias. J Med Genet. 1990;27:559-63.
Sun G, Tang D, Liang J, Wu M. Increasing prevalence of hypospadias associated with various perinatal risk factors in chinese newborns. Urology. 2009;73:1241-5.

Sunderland EM, Hu XC, Dassuncao C, Tokranov AK, Wagner CC, Allen JG. A review of the pathways of human exposure to poly- and perfluoroalkyl substances (PFASs) and present understanding of health effects. J Expo Sci Environ Epidemiol. 2019;29:131-47.

Tai PT, Nishijo M, Kido T, Nakagawa H, Maruzeni S, Naganuma R, et al. Dioxin concentrations in breast milk of Vietnamese nursing mothers: a survey four decades after the herbicide spraying. Environ Sci Technol. 2011; 45:6625-32.

Tang J, Zhai JX. Distribution of polybrominated diphenyl ethers in breast milk, cord blood and placentas: a systematic review. Environ Sci Pollut Res Int. 2017;24:21548-73.

Toft G, Jönsson BA, Bonde JP, Nørgaard-Pedersen B, Hougaard DM, Cohen A, et al. Perfluorooctane sulfonate concentrations in amniotic fluid, biomarkers of fetal Leydig cell function, and cryptorchidism and hypospadias in Danish boys (1980-1996). Environ Health Perspect. 2016;124:151-6.

Vestergren R, Cousins IT, Trudel D, Wormuth M, Scheringer M. Estimating the contribution of precursor compounds in consumer exposure to PFOS and PFOA. Chemosphere. 2008;73: 1617-24.

Vesterholm Jensen D, Christensen J, Virtanen HE, Skakkebæk NE, Main KM, Toppari J, et al. No association between exposure to perfluorinated compounds and congenital cryptorchidism: a nested case-control study among 215 boys from Denmark and Finland. Reproduction. 2014;147:411-7.

Viggiani MT, Polimeno L, Di Leo A, Barone M. Phytoestrogens: dietary intake, bioavailability, and protective mechanisms against colorectal neoproliferative lesions. Nutrients. 2019;11:1709.

Volle DH, Decourteix M, Garo E, McNeilly J, Fenichel P, Auwerx J, et al. The orphan nuclear receptor small heterodimer partner mediates male infertility induced by diethylstilbestrol in mice. J Clin Invest. 2009;119:375264.

Walker BE, Kurth LA. Multi-generational carcinogenesis from diethylstilbestrol investigated by blastocyst transfers in mice. Int J Cancer. 1995;61:249-52.

Wang Z, Cousins IT, Scheringer M, Hungerbühler K. Fluorinated alternatives to long-chain perfluoroalkyl carboxylic acids (PFCAs), perfluoroalkane sulfonic acids (PFSAs) and their potential precursors. Environ Int. 2013;60: 242-8.

Wang Y, Zhong Y, Li J, Zhang J, Lyu B, Zhao Y, et al. Occurrence of perfluoroalkyl substances in matched human serum, urine, hair and nail. J Environ Sci (China). 2018;67:191-7.
Warembourg C, Botton J, Lelong N, Rouget F, Khoshnood B, Le Gléau F, et al. Prenatal exposure to glycol ethers and cryptorchidism and hypospadias: a nested case-control study. Occup Environ Med. 2018;75:59-65.

Watkins DJ, Eliot M, Sathyanarayana S, Calafat AM, Yolton K, Lanphear BP, et al. Variability and predictors of urinary concentrations of phthalate metabolites during early childhood. Environ Sci Technol. 2014;48:8881-90.

Weiss J, Päpke O, Bignert A, Jensen S, Greyerz E, Agostoni $\mathrm{C}$, et al. Concentrations of dioxins and other organochlorines (PCBs, DDTs, $\mathrm{HCHs}$ ) in human milk from Seveso, Milan and a Lombardian rural area in Italy: a study performed 25 years after the heavy dioxin exposure in Seveso. Acta Paediatr. 2003;92:467-72.

White JT, Kovar E, Chambers TM, Sheth KR, Peckham-Gregory EC, O'Neill M, et al. Hypospadias risk from maternal residential exposure to heavy metal hazardous air pollutants. Int J Environ Res Public Health. 2019;16:930.

Willing C, Peich M, Danescu A, Kehlen A, Fowler PA, Hombach-Klonisch S. Estrogen-independent actions of environmentally relevant AhR-agonists in human endometrial epithelial cells. Mol Hum Reprod. 2011;17:115-26.

Winston JJ, Emch M, Meyer RE, Langlois P, Weyer P, Mosley B, et al. Hypospadias and maternal exposure to atrazine via drinking water in the National Birth Defects Prevention study. Environ Health. 2016;15:76.

Wirth JJ, Mijal RS. Adverse effects of low level heavy metal exposure on male reproductive function. Syst Biol Reprod Med. 2010;56:14767.

Yang Y, Workman S, Wilson M. The molecular pathways underlying early gonadal development. J Mol Endocrinol. 2018;JME-17-0314.

Yilmaz B, Terekeci H, Sandal S, Kelestimur F. Endocrine disrupting chemicals: exposure, effects on human health, mechanism of action, models for testing and strategies for prevention. Rev Endocr Metab Disord. 2020;21:12747.

Zhang Y, Dong S, Wang H, Tao S, Kiyama R. Biological impact of environmental polycyclic aromatic hydrocarbons (ePAHs) as endocrine disruptors. Environ Pollut. 2016;213: 809-24.

Zhang C, Schilirò T, Gea M, Bianchi S, Spinello A, Magistrato A, et al. Molecular basis for endocrine disruption by pesticides targeting aromatase and estrogen receptor. Int J Environ Res Public Health. 2020;17:5664.

Zheng Z, Armfield BA, Cohn MJ. Timing of androgen receptor disruption and estrogen exposure underlies a spectrum of congenital penile anomalies. Proc Natl Acad Sci USA. 2015; 112:E7194-203.

Zhu Q, Li H, Wen Z, Wang Y, Li X, Huang T, et al. Perfluoroalkyl substances cause Leydig cell dysfunction as endocrine disruptors. Chemosphere. 2020;253:126764. 